\title{
ARABINOGALACTAN-PROTEINS FROM ECHINACEA PURPUREA: CHARACTERIZATION, LOCALIZATION AND IMMUNOMODULATING PROPERTIES
}

\author{
ㄷ) Classen B.
}

Pharmaceutical Institute, Dept of Pharmaceutical Biology, University of Kiel, Gutenbergstr. 76, 24118 Kiel, Germany

Arabinogalactan-proteins (AGPs) are macromolecular glycoproteins belonging to the putative active compounds of Echinacea preparations (1). ( $\beta$-D-Glc) $)_{3}$ Yariv phenylglycoside specifically binds to most plant AGPS and has been used to isolate AGPs from pressed juice of the aerial parts of Echinacea purpurea L. Moench (Asteraceae). The carbohydrate moiety has been classified as type II arabinogalactan consisting of a backbone of 1,3,6-Galp and 1,3-Galp, with branched side chains composed of 1,3,6-Galp, 1,6-Galp,1,5-Araf, terminal Araf and terminal GlcAp. In the protein part, AGP from pressed juice showed an amino acid sequence rather untypical for AGPs with predominantly contiguous arrangement of three to four Hyp residues in blocks (2). For microscopic localization of AGPs in fresh plant tissue, a new method has been developed. Antibodies against Yariv's reagent have been generated in rabbits and used for immunofluorescent labeling of plant tissue. Xylem tracheary elements showed very strong labeling of the cell wall, especially at the inner side of the wall and in the area of pit canals. Preparations of pressed juice from Echinacea purpurea are used as herbal medicinal products with immunomodulating properties. In vitro, AGP from the pressed juice of herbal material showed complement stimulating activities (3) as well as binding to human leukocytes (4).

References: (1) Classen, B. et al. (2006) Phytomedicine 13: 688-694. (2) Classen, B. et al. (2005) Planta Med. 71: 59-66. (3) Alban, S. et al. (2002) Planta Med. 68: 1118-1124. (4) Thude, S. et al. (2006) Phytomedicine 13: 425-427.

Acknowledgment: The author thanks Rottapharm/Madaus $\mathrm{GmbH}$, Köln, for financial support of this work.

\section{UBIQUINOL IS ANTIHYPOXANT AND CELL ENERGIZER OF THE NEW GENERATION}

\section{(C) Dadali Vladimir A. ${ }^{1}$, Makarov Valery G. ${ }^{2}$}

${ }^{1}$ North-West State Medical University named after I. I. Mechnikov, Saint-Petersburg, Russia

${ }^{2}$ Institute of experimental pharmacology, Saint-Petersburg, Russia

Coenzyme $\mathrm{Q}(\mathrm{CoQ})$ is low molecular component of mitochondrial electron transport chains that functions as molecular shuttle between next some enzymatical complexes: NADH-CoQ-reductase (complex I); succinate-CoQ-reductase (complex II); ubiquinol $\left(\mathrm{CoQH}_{2}\right)$ cytochrome C-reductase (complex III) that with complex IV (cytochrome C-oxidase) realize transformation of carbohydrates, fats and proteins molecular energy into rich energy compounds ATP. CoQ functions in form of quinone redox-cycle ( $Q$-cycle) where oxidized form of CoQ (ox CoQ) via intermediate free radical and anion forms is transformed by enzymaticaly into its active reduce form - ubiquinol $\left(\mathrm{CoQH}_{2}\right)$. Mitochondrial Q-cycle functions so effectively that stimulates transmembrane proton transfer and ATP synthesis twofold more intensively than simple one stage redox process. But redox processes in system (ox) CoQ-CoQH ${ }_{2}$ take place not only in mitochondrion but in another membrane structures - lysosomes, Goldgi and plasma membranes and serum LDL. In lysosomes Q-cycle takes part in proton transfer in $\mathrm{pH}$-dependent activation of Iysosomal pro- teases for the degradation of worked off cell proteins. Another site of (ox) CoQ- $\mathrm{CoQH}_{2}$ action is endosomal pynocytoses that regulates transport of $\mathrm{Fe}^{+2}$ by transferrin into cell cytoplasma. In plasma membranes system (ox) CoQ-CoQH $\mathrm{H}_{2}$ activates of $\mathrm{Na}^{+} / \mathrm{H}^{+}$antiportal proton transfer that with ATP-dependent ion transport determine intracell ion homeostasis. In LDL CoQ (in Co$\mathrm{QH}_{2}$ form) defenses cholesterol and another lipid components from peroxidation. Q-Cycle determines antioxidant-prooxidant functions of $\mathrm{CoQ}$ but $\mathrm{CoQH}_{2}$ only is single stable antioxidant form of CoQ. Moreover it is single enzymatically regenerated endogenic lipid antioxidant. From point of view of $\mathrm{CoQH}_{2}$ formation three enzymatic systems are important: a) NADH-CoQ-oxidoreductase; b) NADH-cytochrome $b_{5}$-reductase; c) NADH/NADPHoxidoreductase (DT-diaphorase). But DT-diaphorase only reduces at once (ox) $\mathrm{CoQ}$ in to $\mathrm{CoQH}_{2}$ by twoelectron transport. Another two enzymes reduce (ox) CoQ via one-electron transfer to semiquinone-radical CoQ ${ }^{-}$that is generated by interaction of $\mathrm{CoQH}_{2}$ with lipid radicals. Besides of right radical scavenging action $\mathrm{Co}-$ 
$\mathrm{QH}_{2}$ take part in cycle regeneration of tocopherol from tocopheroxyl-radicals in biomembranes and serum LDL and formation of ascorbate from ascorbyl-radicals or monohydroascorbate in plasma membranes. Different forms of $\mathrm{CoQ}\left(\mathrm{CoQ}^{-}\right.$and $\mathrm{CoQ}^{-}$) of $\mathrm{Q}$-cycle determine prooxidant functions of $\mathrm{CoQ}$ in reactions: $\mathrm{CoQH}$ $+\mathrm{O}_{2} \Rightarrow \mathrm{CoQ}^{\bullet}+\mathrm{O}_{2}^{-\bullet}+\mathrm{H}^{+}$and $\mathrm{CoQ}^{-\bullet}+\mathrm{O}_{2} \Rightarrow \mathrm{CoQ}+\mathrm{O}_{2}^{-\bullet}$ with formation of $\mathrm{O}_{2}^{-}$in next $\mathrm{H}_{2} \mathrm{O}_{2}$. By means of this factors $\mathrm{Q}$-cycle takes part in regulation of antioxidant - prooxidant balance in corresponding systems and influence on cell redox-dependent signaling cascades that regulate activate of transcriptional factors (including of NF-k $\beta$ ), gene expression, Ca-signal system in heart muscle and apoptoses. Quinone itself takes part in oxidation of thyol groups in growth factor receptors and ion channels and regulates its activity. Afore mentioned molecular mechanisms of $\mathrm{CoQ}$ determine its exceptional role in vital functions of all cells especially energy consumptioning. So CoQ is effective in preventation of numerous mitochondrial diseases (heart diseases, diabetes, metabolic syndrome, neurodegenerative diseases - Alzheimer's, Parkinson's etc.) and with aging as a geroprotector. It is effective in function of immune system (increase of Ig level and relation T-helpers/T-supressors) and in cancer preventation (inhibition of tumor-associated cytokins that stimulate of cancer cells proliferation and decrease vessel growth factor level) Anticancer activity in especially high in combination with anticancer drugs, for example tamoxifen. CoQ may be used as additional correcting factor for the some drugs functions first of all statins and $\beta$-adrenoblockers that being inhibitors of HMGreductase press synthesis of endogenic CoQ. Combination of $\mathrm{CoQ}$ with tocopherol and vitamin $\mathrm{C}$ decrease secondary effect of $\beta$-adrenoblockers, antidepressants and calcium channel blockers and cardiotoxic effects of anticancerogenic drugs (adriamicin, doxorubicin etc). CoQ is necessary component for the metabolic function of L-carnitine (acetyl-L-carnitine, propionyl-L-carnitine etc.), succinic acid and metabolic cardiodrug preductal. But practical application of (ox) CoQ creates some problems that are caused: a) by low absorption in intestine (7-9\%) and therefore by very low bioavailability; b) by lowering of mitochondrial I-III complex enzymatical activity that may be caused by gene mutations, oxidative stress, aging, inhibition by xenobiotics and drugs. This blockage $\mathrm{CoQH}_{2}$ formation and as a result decrease not only of ATP synthesis but and exhaustation of $\mathrm{CoQH}_{2}$ pool in whole. Using of ready forms of $\mathrm{CoQH}_{2}$ is perspective because $\mathrm{CoQH}_{2}$ has bioavailability at eight times more than (ox) CoQ that permit to rich high level of $\mathrm{CoQH}_{2}$ in the blood an in another tissues. We worked out the new effective method of $\mathrm{CoQH}_{2}$ synthesis by catalytic reduction of (ox) CoQ with use nature cell biocompatible compounds with yield $\sim 100 \%$. This open a new wide abilities for effective using of $\mathrm{CoQH}_{2}$ in prophylaxis and therapy.

\section{CATALITIC SYNTHESIS OF COENZYME Q REDUCE FORM AND ITS WATER SOLUBLE MOLECULAR COMPLEXES WITH $\beta$-CYCLODEXTRIN}

\section{(C) Dadali Yury V., Dadali Vladimir A., Makarov Valery G.}

Institute of experimental pharmacology, Saint-Petersburg, Russia

As known usable now in practical medicine substance of CoQ (oxidized form) is characterized by very low bioavailability (absorption in intestine is about 8-9\%) that do not permit to reach of therapeutic concentration in blood. Moreover active form of $\mathrm{CoQ}$ is redused $\mathrm{CoQ}$ - ubiquinol $\left(\mathrm{CoQH}_{2}\right)$. But formation of $\mathrm{CoQH}_{2}$ in mitochondrion is decreased by numerous mitochondrial diseases (diabetes, Alzgeimer's, Parkinson's, cardiac diseases etc.) and with aging. Therefore application of $\mathrm{CoQH}_{2}$ is more reasonable. We have developed the new method of $\mathrm{CoQH}_{2}$ synthesis that is based on catalytic reduction of CoQ with biogenic transition metal ions $\mathrm{Me}^{\mathrm{n}+}$ (redox catalysis) in regenerated by ascorbinic acid active form. Yield of $\mathrm{CoQH}_{2}$ is equal 95-100\%. Duration of synthesis from 10 to 2 minutes that depend from ascorbinic acid and $\mathrm{Me}^{\mathrm{n}+}$ concentration. We demonstrated that reduction of CoQ in aprotonic solvents is realized via triple molecular complex ascorbic acid-Me ${ }^{n+}-\mathrm{CoQ}\left(\lambda_{\max }=358 \mathrm{~nm}\right)$, where $\mathrm{Me}^{\mathrm{n+}}$ play role of electron transfer link between reductive agent and CoQ. Acceleration of reaction take place not only in aprotonic solvents but in another solvents. Quantitatively catalytic reduction of $\mathrm{CoQ}$ is reached at $25^{\circ} \mathrm{C}$ in $60-80$ times more quickly than at $60^{\circ} \mathrm{C}$ without catalysis. Because $\mathrm{Me}^{\mathrm{n}+}$ may stimulate back reaction we have developed method of $\mathrm{Me}^{\mathrm{n}+}$ elimination from system and that stabilize and defense of $\mathrm{CoQH}_{2}$ from oxidation. On the base of this product we have synthesized water soluble molecular complexes $\mathrm{CoQH}_{2}$ with $\beta$-cyclodextrin that in ten times more stable than free $\mathrm{CoQH}_{2}$, Size of this aggregate supramolecular complex is about 200-700 nm (by Coulter's method of corner light scattering). New method of effective accelerate synthesis of ubiquinol $\left(\mathrm{CoQH}_{2}\right)$ and stabilization of water soluble formulation of molecular complexes "CoQH $\mathrm{H}_{2}-$ cyclodextrins" was developed. 